\title{
Effects of temperature on metabolic scaling in black carp
}

\author{
Qian Li ${ }^{1}$, Xiaoling Zhu ${ }^{1}$, Wei Xiong ${ }^{1}$, Yanqiu Zhu ${ }^{1}$, Jianghui Zhang ${ }^{1}$, Pathe Karim DJIBA ${ }^{1}$, Xiao Lv $^{1}$, Yiping Luo \\ Corresp. 1 \\ ${ }^{1}$ Key Laboratory of Freshwater Fish Reproduction and Development, Ministry of Education, School of Life Sciences, Southwest University, Chongqing, \\ China \\ Corresponding Author: Yiping Luo \\ Email address: luoguo@swu.edu.cn
}

The surface area (SA) of organs and cells may vary with temperature, which changes the SA exchange limitation on metabolic flows as well as the influence of temperature on metabolic scaling. The effect of SA change can intensify (when the effect is the same as that of temperature) or compensate for (when the effect is the opposite of that of temperature) the negative effects of temperature on metabolic scaling, which can result in multiple patterns of metabolic scaling with temperature among species. The present study aimed to examine whether metabolic scaling in black carp changes with temperature and to identify the link between metabolic scaling and SA at the organ and cellular levels at different temperatures. The resting metabolic rate (RMR), gill surface area (GSA), and red blood cell (RBC) size of black carp with different body masses were measured at $10^{\circ} \mathrm{C}$ and $25^{\circ} \mathrm{C}$, and the scaling exponents of these parameters were compared. The results showed that both body mass and temperature independently affected the RMR, GSA, and RBC size of black carp. A consistent scaling exponent of RMR $(0.764,95 \% \mathrm{Cl}: 0.718-0.809)$ was obtained for both temperatures. The RMR at $25^{\circ} \mathrm{C}$ was 2.7 times higher than that at $10^{\circ} \mathrm{C}$. At both temperatures, the GSA scaled consistently with body mass by an exponent of 0.802 (95\% Cl: 0.759-0.846), while RBC size scaled consistently with body mass by an exponent of $0.042(95 \% \mathrm{Cl}: 0.010,0.075)$. The constant GSA scaling can explain the constant metabolic scaling as temperature increases, as metabolism may be constrained by fluxes across surfaces. The GSA at $10^{\circ} \mathrm{C}$ was 1.2 times higher than that at $25^{\circ} \mathrm{C}$, which suggests that the constraints of GSA on the metabolism of black carp is induced by the higher temperature. The RBC size at $10^{\circ} \mathrm{C}$ was 1.1 times higher than that at $25^{\circ} \mathrm{C}$. The smaller RBC size (a larger surface-to-volume ratio) at higher temperature suggests an enhanced oxygen supply and a reduced surface boundary limit on $b_{R}$, which offset the negative effect of temperature on $b_{\mathrm{R}}$. 
1 Effects of temperature on metabolic scaling in black carp

2 Qian Li, Xiaoling Zhu, Wei Xiong, Yanqiu Zhu, Jianghui Zhang, Pathe Karim DJIBA, Xiao Lv, 3 Yiping Luo

4 Key Laboratory of Freshwater Fish Reproduction and Development, Ministry of Education, 5 School of Life Sciences, Southwest University, Chongqing, 400715 China

6

7 Corresponding author:

8 Yiping Luo, Key Laboratory of Freshwater Fish Reproduction and Development, Ministry of 9 Education, School of Life Sciences, Southwest University, Chongqing, 400715 China Tel./Fax: 10 +86 236-825-3505; E-mail: luoguo@swu.edu.cn. 


\section{Abstract}

The surface area (SA) of organs and cells may vary with temperature, which changes the SA exchange limitation on metabolic flows as well as the influence of temperature on metabolic scaling. The effect of SA change can intensify (when the effect is the same as that of temperature) or compensate for (when the effect is the opposite of that of temperature) the negative effects of temperature on metabolic scaling, which can result in multiple patterns of metabolic scaling with temperature among species. The present study aimed to examine whether metabolic scaling in black carp changes with temperature and to identify the link between metabolic scaling and SA at the organ and cellular levels at different temperatures. The resting metabolic rate (RMR), gill surface area (GSA), and red blood cell (RBC) size of black carp with different body masses were measured at $10^{\circ} \mathrm{C}$ and $25^{\circ} \mathrm{C}$, and the scaling exponents of these parameters were compared. The results showed that both body mass and temperature independently affected the RMR, GSA, and RBC size of black carp. A consistent scaling exponent of RMR (0.764, 95\% CI: 0.718-0.809) was obtained for both temperatures. The RMR at $25^{\circ} \mathrm{C}$ was 2.7 times higher than that at $10^{\circ} \mathrm{C}$. At both temperatures, the GSA scaled consistently with body mass by an exponent of 0.802 (95\% CI: 0.759-0.846), while RBC size scaled consistently with body mass by an exponent of 0.042 (95\% CI: 0.010, 0.075). The constant GSA scaling can explain the constant metabolic scaling as temperature increases, as metabolism may be constrained by fluxes across surfaces. The GSA at $10^{\circ} \mathrm{C}$ was 1.2 times higher than that at $25^{\circ} \mathrm{C}$, which suggests that the constraints of GSA on the metabolism of black carp is induced by the higher temperature. The $\mathrm{RBC}$ size at $10^{\circ} \mathrm{C}$ was 1.1 times higher than that at $25^{\circ} \mathrm{C}$. The smaller RBC size (a larger surface-to-volume ratio) at higher temperature suggests an enhanced oxygen supply and a reduced surface boundary limit on $b_{\mathrm{R}}$, which offset the negative effect of temperature on $b_{\mathrm{R}}$.

\section{Introduction}

The relationship between the metabolic rate (MR) and body mass $(M)$ of organisms can be expressed as a power-law function, $\mathrm{MR}=a M^{b}$, where $a$ is a constant and $b$ is the scaling exponent. The mechanisms of metabolic scaling have been attributed to the ontogenetic changes in the components of active organs (the organ size theory) (Itazawa and Oikawa 1983; Oikawa et al. 1992), the fractal patterns of resource distributions (the metabolic theory of ecology) (West et al. 1997; Brown et al. 2004), the limitations on surfaces for mass and/or energy exchange (the surface 
area (SA) hypothesis) (Rubner 1883; Okie 2013), the ontogenetic change in the ratio of cell SA to volume (cell metabolic hypothesis) (Davison 1955; Kozłowski et al. 2003; Starostová et al. 2009), and the effects of SA vs. the volume-related metabolic processes of organisms mediated by metabolic level (the metabolic level boundaries hypothesis) (Glazier 2005, 2008, 2009, 2010). However, the underlying mechanisms of metabolic scaling remain unclear. Recently, a growing number of studies have implied that, in addition to the SA and metabolic level of whole organisms, SA at the organ level and the cellular level and their scaling may contribute to the allometric scaling of MR (Okie 2013; Hirst 2014; Luo et al. 2015, 2020; Gillooly et al. 2016; Li et al. 2018). It is of interest to investigate whether the changes in SA at the organ and cellular levels affect the metabolic scaling of the whole body of an organism.

Temperature is a major factor that affects MR and its scaling with body mass. Generally, the resting MR (RMR) of ectotherms increases with increasing temperature (Jobling 1994; Clarke and Johnston 1999). In fish, RMR increases with temperature by a coefficient $\left(\mathrm{Q}_{10}\right)$ ranging from 1.652.70 (Jobling 1994; Clarke and Johnston 1999; Peck et al. 2005; Ohlberger et al. 2007). However, the changes in the exponent $b$ of the RMR $\left(b_{\mathrm{R}}\right)$ with temperature vary among species. In most cases, $b_{\mathrm{R}}$ is reduced by increasing temperature (Xie and Sun 1990; Ohlberger et al. 2007, 2008, 2012; Killen et al. 2010; Li et al. 2018), which can be explained according to the metabolic level boundaries hypothesis (Glazier 2005, 2008, 2009, 2010, 2014). At high temperatures, high metabolic demand results in metabolic scaling being primarily determined by fluxes across surfaces (scaling as $M^{2 / 3}$ ). However, at low temperatures, low metabolic demand can be met by surface-related processes, and therefore metabolic scaling is determined more by the energy demand required to sustain the tissues (scaling as $M^{1}$ ). Thus, $b_{\mathrm{R}}$ should decrease as temperature increases (Glazier 2005, 2008, 2009, 2010, 2014). However, increased and/or unchanged $b_{\mathrm{R}}$ with temperature was observed in studies of the gastropod Littorina littorea (Newell 1973), cuttlefish (Sepia officinalis) (Melzner 2007; Grigoriou 2009), krill (Euphausia pacifica) (Paranjape 1967), and several salamanders (Gifford et al. 2013). In fishes, fluctuating and/or unchanged $b_{\mathrm{R}}$ with temperature has been reported in several species of cyprinids and was speculated to be due to species-specific phenotypically plastic responses or to increasing spontaneous activity with temperature (Hölker 2003, 2006; Luo and Wang 2012; Ohlberger et al. 2012). It remains unclear why $b_{\mathrm{R}}$ can change with temperature in different patterns.

Previous studies have shown that the gill surface area (GSA) of fish may vary with temperature. 
For example, a thermally plastic increase in GSA has been observed in several species of cyprinids and has been suggested to be an adaptation of the fish to cope with its high metabolic demand with limited oxygen availability in warmer water (Sollid et al. 2005; Sollid and Nilsson 2006; Chen et al. 2019). However, temperature may not affect the mass scaling exponents of GSA $\left(b_{\mathrm{G}}\right)$ of fish (Li et al. 2018). It remains under debate whether GSA reflects metabolic demands (Lefevre et al. 2017, 2018) or, in contrast, is a constraint on the metabolic rates of fish (Pauly 1981; Pauly and Cheung 2018a, b). In any case, GSA and its scaling should be relevant to metabolic rate and metabolic scaling. For example, $b_{\mathrm{G}}$ is very close to $b_{\mathrm{R}}$ in several species of carp, especially when controlling the effect of ventilation rate (Luo et al. 2020). Therefore, the determination of the GSA of fish at different temperatures may supply explanations for the effect of temperature on $b_{\mathrm{R}}$.

The cell sizes of ectotherms can vary with temperature. The reduced cell size at warmer temperatures may increase the relative SA and improve the oxygen supply (Audzijonyte et al. 2019). The red blood cell (RBC) size is usually adopted as a proxy for the general cell size of an organism (Starostová et al. 2009, 2013; Luo et al. 2015). Many studies have observed that the sizes of RBCs decrease with increasing temperature in ectotherms (Van Voorhies 1996; Goodman and Heah 2010; Hermaniuk et al. 2016). It remains unclear whether the thermally reduced cell size compensates for the negative effect of temperature on $b_{\mathrm{R}}$. The RBC size of fish generally scales with body mass by a very small exponent $\left(b_{\mathrm{C}}, 0-0.1\right)$ with a weak correlation with body mass (Huang et al. 2013; Zhang et al. 2014; Luo et al. 2015). It can be expected that temperature change may not induce a remarkable change in the $b_{\mathrm{C}}$ of fish.

It can be predicted from the above backgrounds that the thermal plastic changes in SA at both the organ and cellular levels may change the limitation of the exchange surface on metabolic flows and therefore change the influence of temperature on metabolic scaling. If SA decreases with temperature, the limiting effect of SA further intensifies the negative effect of temperature on metabolic scaling, which results in decreased $b_{\mathrm{R}}$ values as temperature increases. In contrast, if SA increases with temperature, the reduced limiting effect of SA compensates for the negative effect of temperature on metabolic scaling, which may result in unchanged and/or increased $b_{\mathrm{R}}$ values as temperature increases.

Black carp (Mylopharyngodon piceus), a freshwater cyprinid fish native to rivers and lakes of China, was selected as the experimental animal in the present study. This species has been introduced into multiple regions of the world, including Europe, West-Central Asia, and North 
105 America, and has been suggested to have serious adverse impacts on native aquatic communities 106 due to predation on mollusc species (Nico and Neilson 2019). This fish is tolerant of water

107 108 temperatures from approximately $0.5-40^{\circ} \mathrm{C}$, and its optimum water temperatures range from 18 to $30^{\circ} \mathrm{C}$ for adults (CABI 2019). Information on the physiological response of black carp to temperature change would be useful for understanding its wide spread and for controlling its negative impacts on aquatic ecosystems. However, little is known regarding the effects of temperature on the physiology of this fish. A previous study showed that black carp could remodel their gill morphology to increase GSA under hypoxic conditions (Dhillon et al. 2013). Our recent studies have determined the metabolic scaling of black carp and suggested that both GSA and RBC size may affect the metabolic scaling of carp (Lv et al. 2018; Luo et al. 2020). It remains unclear how temperature affects the RMR and $b_{\mathrm{R}}$ of black carp and how temperature affects its GSA and RBC size and scaling.

The present study aimed to examine whether metabolic scaling in black carp changes with temperature and to determine the link between metabolic scaling and SA at the organ and cellular levels at different temperatures. Therefore, the RMR, GSA, and RBC size of black carp were determined at $10^{\circ} \mathrm{C}$ and $25^{\circ} \mathrm{C}$, and their scaling exponents were analyzed. We hypothesized that as temperature increases, 1) RMR increases, and $b_{\mathrm{R}}$ decreases; 2) GSA increases, and $b_{\mathrm{G}}$ does not change; and 3) RBC size decreases, but $b_{\mathrm{C}}$ does not change.

\section{Materials and Methods}

\section{Experimental processes}

Black carp (body mass ranging from 5 to $250 \mathrm{~g}, \mathrm{n}=70$ ) were obtained from Xiema aquaculture farm in Beibei, Chongqing, China and transferred to the laboratory. All experimental processes were performed according to the ethical requirements for animal care of the School of Life Sciences of Southwest University, China (LS-SWU/012/2016), and the requirements for the living environment and housing facilities for laboratory animals in China (Gb/T14925-2001). The fish were acclimated in a rearing system at their original temperature $\left(17.0^{\circ} \mathrm{C}\right)$ for two weeks, and the variations in temperature were kept within $\pm 0.2^{\circ} \mathrm{C}$ using a heater (JRB-250, Sunsun CO., Ltd, Zhejiang, China) regulated by an automatic temperature controller (PY-SM5, Pinyi CO., Ltd, Zhejiang, China). The dissolved oxygen concentration was kept above 95\% saturation by continuous air pumping. Water temperature and oxygen concentration were checked twice daily 
136 (08:30 and 18:30) using a fiber-optic oxygen sensor probe connected with a portable multimeter 137 (HQ30D, Hach Company, Loveland CO, USA). The ammonia concentration of the rearing water

138

139

140

141

142

143

144

145

146

147

148

149

150

151

152

153

154

155

156

157

158

159

160

161

162

163

164

165

166 was monitored once daily (08:30) using the salicylate-hypochlorite method (Verdouw et al. 1978). One-third of the volume of the rearing water was refreshed with aerated tap water every day (09:00) to keep the ammonia-N level below $0.01 \mathrm{mg} \mathrm{L}^{-1}$. The photoperiod was $12 \mathrm{~h}$ : $12 \mathrm{~h}$ light: dark. During acclimation, the fish were fed a commercial diet to satiation once daily (18:00), and the residual pellets were sucked out with a siphon one hour after feeding to ensure that the water was clean. The main chemical composition of the commercial diet was $12.5 \%$ moisture, $33.0 \%$ protein, $3.0 \%$ fat and $10.0 \%$ digestible carbohydrate (Tongwei Company, Sichuan, China). At the end of acclimation, the fish were randomly divided into two groups ( $n=35$ for each group) for the temperature treatments. The fish of each group were reared in five tanks with seven individuals per tank. The tank sizes were $80 \mathrm{~cm} \times 60 \mathrm{~cm} \times 50 \mathrm{~cm}$, and the water volume was $192 \mathrm{~L}$ in each tank. The water in each tank was recirculated through a filtration system (HBL803, Sunsun CO., $\mathrm{Ltd}$, Zhejiang, China). One group was warmed to $25^{\circ} \mathrm{C}$ by $1^{\circ} \mathrm{C}$ per day using a heater (JRB-250, Sunsun CO., Ltd, Zhejiang, China) and an automatic temperature controller (PY-SM5, Pinyi CO., Ltd, Zhejiang, China). The other group was cooled by $1{ }^{\circ} \mathrm{C}$ per day to $10^{\circ} \mathrm{C}$ using a cooling water machine (CW1000A, Risheng CO., Ltd, Guangdong, China) and an automatic temperature controller (PY-SM5, Pinyi CO., Ltd, Zhejiang, China). Thereafter, the fish were reared at $10.0 \pm 0.2^{\circ} \mathrm{C}$ and $25.0 \pm 0.2^{\circ} \mathrm{C}$ for 2 weeks. The water quality monitoring and feeding processes were the same as those adopted during the abovementioned acclimation period. As one individual died during the $25^{\circ} \mathrm{C}$ trial period, the final numbers of fish specimens were 34 for the $25^{\circ} \mathrm{C}$ treatment and 35 for the $10^{\circ} \mathrm{C}$ trial period.

The oxygen consumption rate was measured by a continuous flow-through respirometer and was used to represent the MR of individual fish (Wang et al. 2012). The structure of the respirometer is described in $\mathrm{Fu}$ et al. (2005). At the end of the temperature trial period, the fish were fasted for $48 \mathrm{~h}$ and individually placed into the respirometer chambers overnight before the determination of oxygen consumption. Chambers of different sizes $(0.03,0.13,0.52,0.86$, and $1.20 \mathrm{~L}$ ) were used depending on the size of the experimental individual, ensuring that the fish body could stretch to its full length but could not be inverted. Fifteen chambers were used at the same time for measurements, and one chamber without fish was used as the control to determine the background oxygen consumption. All chambers were placed in a water bath 
$167(110 \mathrm{~cm} \times 70 \mathrm{~cm} \times 30 \mathrm{~cm})$. The visual field of the fish was shielded by the water bath to avoid visual 168 disturbance by the experimental operation. The water flow rate was adjusted by regulating the

169

170

171

172

173

174

175

176

177

178

179

180

181

182

183

184

185

186

187

188

189

190

191

192

193

194

195

196

197 valve at the inlet of each chamber prior to measurements. The outflow water from the respiration chamber was collected using a volumetric flask of a given volume, for which the time duration was recorded by a stopwatch. Then, the water flow velocity $\left(v, 1 \mathrm{~h}^{-1}\right)$ was calculated. The flow rate was regulated to ensure that the dissolved oxygen in the outlet water of each breathing chamber was approximately $0.5-1 \mathrm{mg} \mathrm{L}^{-1}$ lower than that of the control chamber but higher than $70 \%$ saturation concentration to avoid stress on the experimental fish due to lack of oxygen (Blaikie et al. 1996; Fu and Xie 2004). The dissolved oxygen concentration was measured at the outlet of the chamber using a probe connected with a portable multimeter (HQ30D, Hach Company, Loveland $\mathrm{CO}$, USA). The oxygen consumption rate of each fish $\left(\dot{M} \mathrm{O}_{2}, \mathrm{mg} \mathrm{O}_{2} \mathrm{~h}^{-1}\right)$ was calculated by the following formula:

where $\Delta \mathrm{O}_{2}$ is the difference between the dissolved oxygen concentrations $\left(\mathrm{mg} \mathrm{O}_{2} \mathrm{~L}^{-1}\right)$ of the outlets of the experimental chamber and the control chamber, and $v$ is the water flow rate through the chamber $\left(\mathrm{L} \mathrm{h}^{-1}\right)$. The individual oxygen consumption rate was measured hourly from 09:00 to 15:00, and the mean value of the lowest two measurements was used as the RMR for that individual. The mean value of $\mathrm{Q}_{10}$ of $\mathrm{RMR}$ over the range $10-25^{\circ} \mathrm{C}$ was calculated by $\mathrm{Q}_{10}=$ $\left[\left(\mathrm{RMR}_{25} / \mathrm{RMR}_{10}\right)\right]^{10 / 15}$, where $\mathrm{RMR}_{25}$ and $\mathrm{RMR}_{10}$ are the mass-corrected mean values of the $\mathrm{RMRs}$ at 25 and $10^{\circ} \mathrm{C}$, respectively.

After the determination of RMR, the fish were anesthetized for blood and gill arch sampling with $0.15 \mathrm{~g} \mathrm{~L}^{-1}$ tricaine methanesulfonate (MS-222) for five minutes. Blood was taken from the caudal vessel using an anticoagulant-treated $\left(0.04 \mathrm{mg} \mathrm{mL}^{-1}\right.$ sodium heparin) syringe and was transferred to an anticoagulant-treated centrifuge tube on ice. The blood sampling procedure was finished within one minute. Then, blood smears were made immediately. A blood smear failed for one individual at $25^{\circ} \mathrm{C}$ because of the difficulty of sampling blood from a very small individual. The left four gill arches were dissected, kept in Bouin's fluid for 2 days and stored in 70\% alcohol for several days (less than one week) before the GSA was measured. After blood and gill arch sampling, the fish were killed while anesthetized by quick freezing in liquid nitrogen since the fish were not capable of suffering while unconscious. Since the experimental animals were farmed fish, criteria for euthanizing the animals did not need to be established prior to the planned end of the 
198

199

200

201

202

203

204

205

206

207

208

209

210

211

212

213

214

215

216

217

218

219

220

221

222

223

224

225

226

227

228

experiment.

Blood smears were made with Wright-Giemsa dye solution (Gao et al. 2007; Huang et al. 2013). Fifty erythrocytes were randomly selected from the stained blood smears to determine the cell length $(\mathrm{LC}, \mu \mathrm{m})$ and cell width (WC, $\mu \mathrm{m})$ using a microscope (EV5680B, Aigo Company, China) and Image-Pro Plus 6.0 software (Media Cybernetics, Rockville, MD, USA). The red blood cell area $\left(S_{\mathrm{RBC}}, \mu \mathrm{m}^{2}\right)$ was calculated as $S_{\mathrm{RBC}}=\mathrm{LC} \times \mathrm{WC} \times \pi / 4$. The GSAs were determined according to the methods described by Li et al. (2018). Briefly, the GSA was calculated by a standardized gill morphology assessment (Hughes 1966, 1984). The filament number on each gill arch was counted, and six filaments were sampled from each arch to measure the filament length and the secondary lamellae frequency. Three secondary lamellae were chosen from each of the six sampled filaments of the second arch to determine the bilateral areas of the lamella. The bilateral lamellae areas were determined using a microscope (EV5680B, Aigo Digital Technology Co., Beijing, China) and Image-Pro Plus 6.0 software (Media Cybernetics, Rockville, MD, USA). The total length of all the gill filaments (TL, mm), the mean lamella frequency (LF, $\mathrm{mm}^{-1}$ ), and the mean lamella area $\left(\mathrm{LA} \mathrm{mm}^{2}\right)$ were obtained. The GSA $\left(\mathrm{mm}^{2}\right)$ of an individual was calculated by the following formula: GSA $=4 \times \mathrm{TL} \times \mathrm{LF} \times \mathrm{LA}$. The GSA determination failed for one individual at each temperature because of the difficulty of working with very small individuals. The raw data are in the supplementary files.

\section{Statistical analysis}

The data were calculated using Microsoft Excel 2003 (Microsoft Corporation, Redmond, WA, USA) and were analyzed using R (R Development Core Team 2018). The original data for variables including RMR, $S_{\mathrm{RBC}}$, and GSA were log10 transformed. An ANCOVA (aov) was performed to analyze the effects of temperature and body mass on RMR, $S_{\mathrm{RBC}}$, and GSA, using temperature as the categorical factor and body mass as the covariate. If the interaction between body mass and temperature was significant, ordinary least squares regression $(1 \mathrm{~m})$ was performed on the RMR, $S_{\mathrm{RBC}}$, and GSA data with body mass as the independent variable for each temperature. If the interaction between body mass and temperature was not significant, the regression analysis was performed on the RMR, $S_{\mathrm{RBC}}$, and GSA data with both body mass and temperature as independent variables. The linear regression slopes for the RMR and the GSA were compared at each temperature. The $b$ values were expressed with 95\% confidence intervals (CIs) and compared 
229 to given values using a $t$-test. The ordinary least squares regression $(\mathrm{lm})$ was used to analyze the 230 mass-independent correlations between the residual values of RMR, $S_{\mathrm{RBC}}$, and GSA. The 231 significance level was $P<0.05$.

232

233

234

235

236

237

238

239

240

241

242

243

244

245

246

247

\section{Results}

The results showed that both body mass $(F=1021.04, P<0.001)$ and temperature $(F=648.44, P$ $<0.001)$ affected the RMR of black carp, with no significant interaction between body mass and temperature $(F=1.02, P=0.317)$. Therefore, a consistent $b_{\mathrm{R}}(0.764,95 \% \mathrm{CI}: 0.718-0.809)$ between temperatures was obtained based on the regression with log body mass and temperature as independent variables (Fig. 1). The value of $b_{\mathrm{R}}$ was significantly larger than $2 / 3(t=4.31, P<$ $0.001)$ but not larger than $3 / 4(t=0.62, P=0.537)$. The mass-specific RMR ranged from 81.8 to $216.6 \mathrm{mg} \mathrm{O}_{2} \mathrm{~kg}^{-1} \mathrm{~h}^{-1}$ at $25^{\circ} \mathrm{C}$ and from 22.3 to $96.9 \mathrm{mg} \mathrm{O}_{2} \mathrm{~kg}^{-1} \mathrm{~h}^{-1}$ at $10^{\circ} \mathrm{C}$. The $\mathrm{RMR}$ at $25^{\circ} \mathrm{C}$ was 2.7 times higher than that at $10^{\circ} \mathrm{C}$ when corrected to the mean values for the body masses, representing a $\mathrm{Q}_{10}$ value of 1.95 .

The interaction between body mass and temperature had no significant effect on GSA $(F=$ $0.005, P=0.943)$. Both body mass $(F=1389.42, P<0.001)$ and temperature $(F=33.27, P<$ $0.001)$ significantly affected GSA. GSA scaled consistently with body mass at both temperatures (Fig. 2), and $b_{\mathrm{GSA}}(0.802,95 \% \mathrm{CI}$ : 0.759-0.846) was significantly higher than $2 / 3(t=6.21, P<$ $0.001)$ but was not different from the $b_{\mathrm{R}}$ value $\left(F=1.87, P=0.176\right.$ at $10^{\circ} \mathrm{C} ; F=1.39, P=0.24$ at $25^{\circ} \mathrm{C}$ ). When controlling for the effects of body mass, the GSA at $10^{\circ} \mathrm{C}$ was 1.2 times higher than that at $25^{\circ} \mathrm{C}$. No significant correlation was found between GSA and RMR when controlling for body mass $\left(r^{2}=-0.0134, P=0.719\right)$ (Fig. S1).

The interaction between body mass and temperature had no significant effect on $S_{\mathrm{RBC}}(F=0.01$, $P=0.921)$. Both body mass $(F=7.68, P=0.007)$ and temperature $(F=12.61, P<0.001)$ significantly affected $S_{\mathrm{RBC}}$. $S_{\mathrm{RBC}}$ scaled consistently with body mass at both temperatures by a $b_{\mathrm{C}}$ of 0.042 (95\% CI: $0.010,0.075)$ (Fig. 3). However, there was only a weak correlation between $S_{\mathrm{RBC}}$ and body mass $\left(r^{2}=0.217\right)$. When controlling for the effects of body mass, the $S_{\mathrm{RBC}}$ at $10^{\circ} \mathrm{C}$ was 1.1 times higher than that at $25^{\circ} \mathrm{C}$. No significant correlation was found between $S_{\mathrm{RBC}}$ and RMR when controlling for body mass $\left(r^{2}=-0.0133, P=0.728\right)$ (Fig. S2).

Discussion 
260 In the present study, the RMR of black carp increased with increasing temperature. The $\mathrm{Q}_{10}$ value 261 (1.95) was within the $\mathrm{Q}_{10}$ value range (1.65-2.70) of the RMR of most previously reported fish 262 (Jobling 1994; Peck et al. 2005; Ohlberger et al. 2007), suggesting that the metabolic level of black 263 carp is moderately sensitive to temperature. However, inconsistent with our prediction, the results 264 showed that the effect of body mass on the RMR of black carp was independent of temperature, 265 i.e., the increased metabolic level with increasing temperature did not reduce the $b_{\mathrm{R}}$ of the black 266 carp.

267 In addition, in contrast to our prediction, the GSA of black carp decreased with increasing temperature. Therefore, black carp does not increase its GSA to cope with the high metabolic demand in warmer water, in contrast to previously reported fish (Sollid et al. 2005; Sollid and Nilsson 2006; Chen et al. 2019). Changes in the GSA of fish have relevance not only to oxygen supply/demand but also to ion exchange and parasitic infections (Pauly 1981; Lefevre et al. 2017, 2018; Pauly and Cheung 2018a, b). Reducing GSA can help decrease losses of ions and risk of infections in warmer water. In addition to GSA, the ventilation rate could regulate oxygen supplies (Luo et al. 2020; Xiong et al. 2020). Therefore, an increase in RMR with increasing temperature is not necessarily accompanied by an increase in GSA. The results suggest that GSA may not reflect metabolic demands, as proposed by Lefevre et al. $(2017,2018)$. In contrast, the constraints of GSA on the metabolism of black carp may be enhanced at higher temperatures. However, the $b_{\mathrm{R}}$ of the fish did not decrease with increasing temperature. There are several possible causes that can counteract the negative effect of temperature on the $b_{\mathrm{R}}$. First, the spontaneous activity of the fish may increase at high temperatures, which causes the metabolic rate to be increasingly dominated by the energy demands of muscular tissue, which is directly proportional to muscle mass $(b=1)$ and can result in a positive effect on $b_{\mathrm{R}}$ at high temperatures (Luo and Wang 2012; Glazier 2014). Second, similar to previous results in many ectotherms (Van voorhies,1996; Goodman and Heah 2010; Hermaniuk et al. 2016), our study found that black carp have a smaller RBC size (a larger surface-to-volume ratio) at higher temperatures, which may enhance the oxygen supply and weaken the effect of the surface boundary limit on $b_{\mathrm{R}}$ (Glazier 2005, 2010; Luo et al. 2015). Thus, the negative effect of temperature on $b_{\mathrm{R}}$ was compensated. Third, the metabolic rate should be determined by fluxes across surfaces; therefore, metabolic scaling should be determined by SA scaling (Wells and Pinder 1996 a, b; Reich 2001; Yoshiyama and Klausmeier 2008; 290 Kooijman 2009; Phillips et al. 2009; Glazier et al. 2015; Luo et al. 2020). Therefore, when SA 
291 scaling remains unchanged as temperature increases, metabolic scaling should remain constant.

292 Accordingly, our results showed no difference between the $b_{\mathrm{R}}$ and $b_{\mathrm{GSA}}$ of black carp at either 293 temperature. Indeed, even though the $b_{\mathrm{R}}$ of many fishes decrease with increasing temperature (Xie 294 and Sun 1992; Ohlberger et al. 2007, 2008, 2012; Li et al. 2018), a fluctuating and/or unchanged $295 b_{\mathrm{R}}$ was observed in several fishes, e.g., Coreius guichenoti (Luo and Wang 2012), Abramis brama, 296 and Rutilus rutilus (Hölker 2003, 2006; Ohlberger et al. 2012).

297 The temperature-induced change in exchange surfaces at the individual level may play a role in 298 the metabolic scaling of fish (Li et al. 2018). In the present results, the different GSA and $S_{\mathrm{RBC}}$ at 299 different temperatures suggest that plasticity in exchange surfaces may occur both at the individual

300

301

302

303

304

305

306

307

308

309

310

311

\section{Conclusion}

313

314

315

316

317

318

319

320

321 temperatures.

level and at the cellular level. The cell metabolic hypothesis proposed that metabolic level negatively correlates with the cell size of organisms (Davison 1955; Kozłowski et al. 2003; Starostová et al. 2013). However, the present results showed no negative correlation between RMR and $S_{\mathrm{RBC}}$ in black carp. The results were not surprising, as correlations between RMR and $S_{\mathrm{RBC}}$ vary among fish species (Maciak et al. 2011; Huang et al. 2013; Zhang et al. 2014; Luo et al. 2015; Lv et al. 2018). According to the cell metabolic hypothesis, $b_{\mathrm{R}}$ equals 1 when the cell size scales as $\mathrm{M}^{0}$ and 2/3 when the cell size scales as $\mathrm{M}^{2 / 3}$ (Davison 1955; Szarski 1983; Kozłowski et al. 2003). In the present study, the RBC size scaled with body mass by a very small exponent (0.042), which predicts a metabolic scaling exponent very close to 1 according to the cell metabolic hypothesis. However, the observed $b_{\mathrm{R}}$ value in black carp was 0.764 . Therefore, ontogenetic changes in cell size may not contribute much to the metabolic scaling of black carp.

In conclusion, the present study provides comparative data on SA parameters and RMR at the organismal and cellular level, as well as the mass scaling exponents of black carp at different temperatures. These RMRs increased while both GSA and $S_{\mathrm{RBC}}$ decreased with increasing temperature. No significant difference in $b_{\mathrm{R}}, b_{\mathrm{G}}$, or $b_{\mathrm{C}}$ exists between temperatures. This indicates that the negative effect of temperature on the metabolic scaling exponent is offset by other factors, e.g., increasing spontaneous activity, decreasing cell size, and constant GSA scaling at higher

\section{Acknowledgments}


322 We thank Mr. Bo Zhang for his help with fish collection. We sincerely thank the anonymous 323 reviewers for their helpful suggestions and comments.

324 
325

326

327

328

329

330

331

332

333

334

335

336

337

338

339

340

341

342

343

344

345

346

347

348

349

350

351

352

353

354

355

\section{References}

Audzijonyte, A., Barneche, D.R., Baudron, A.R., Belmaker, J., Clark, T., Marshall, C.T., Morrongiello, J.R. and Van Rijn, I. (2019). Is oxygen limitation in warming waters a valid mechanism to explain decreased body sizes in aquatic ectotherms. Global Ecol. Biogeogr. 28: 64-77.

Blaikie, H.B. and Kerr, S.R. (1996). Effect of activity level on apparent heat increment in Atlantic cod, Gadus morhua. Can. J. Fish. Aquat. Sci. 53: 2093-2099.

Brett, J.B. and Glass, N.R. (1973). Metabolic rates and critical swimming speeds of sockeye salmon (Oncorhynchus nerka) in relation to size and temperature. J. Fish. Res. Board Can. 30(3): 379-387.

Brown, J.H., Gillooly, J.F., Allen, A.P., Savage, V.M. and West, G.B. (2004). Toward a metabolic theory of ecology. Ecology 85: 1771-1789.

CABI. (2019). Mylopharyngodon piceus (black amur). In Invasive species compendium. CAB International, Wallingford, U.K. Available: https://www.cabi.org/ISC/datasheet/73511

Chen, B., Fu, S., Cao, Z. and Wang, Y. (2019). Effect of temperature on critical oxygen tension $\left(\mathrm{P}_{\text {crit }}\right)$ and gill morphology in six cyprinids in the Yangtze River, China. Aquaculture 508: 137-146.

Clarke, A. and Johnston, N.M. (1999). Scaling of metabolic rate with body mass and temperature in teleost fish. J. Anim. Ecol. 68: 893-905.

Davison J. (1955). Body weight, cell surface and metabolic rate in anuran Amphibia. Biol. Bull. 109: 407-419.

Dhillon, R.S., Yao, L., Matey, V., Chen, B., Zhang, A., Cao, Z.D., Fu, S.J., Brauner, C.J., Wang, Y.X. and Richards, J.G. (2013). Interspecific differences in hypoxia-induced gill remodeling in carp. Physiol. Biochem. Zool. 86: 727-739.

Fu, S.J. and Xie, X.J. (2004). Nutritional homeostasis in carnivorous southern catfish (Silurus meridionalis Chen): is there a mechanism for increased energy expenditure during carbohydrate overfeeding? Comp. Biochem. Physiol. A. 139: 359-363.

Fu, S.J., Xie, X. and Cao, Z.D. (2005). Effect of dietary composition on specific dynamic action in southern catfish Silurus meridionalis Chen. Aquac. Res. 36(14): 1384-1390.

Gao, Z.X., Wang, W.M., Abbas, K., Zhou, X.Y., Yang, Y., Diana, J.S., Wang, H.P., Wang, H.L., Li, Y. and Sun, Y.H. (2007). Haematological characterization of loach Misgurnus 
356

357

358

359

360

361

362

363

364

365

366

367

368

369

370

371

372

373

374

375

376

377

378

379

380

381

382

383

384

385

386

anguillicaudatus: Comparison among diploid, triploid and tetraploid specimens. Comp. Biochem. Physiol. A. 147: 1001-1008.

Gifford, M., Timothy A.C. and William, E.P. (2013). The effects of temperature and activity on intraspecific scaling of metabolic rates in a lungless salamander. J. Exp. Zool. A. 319: 230-6.

Giguere, L.A., Cote, B., and Stpierre, J. (1988). Metabolic rates scale isometrically in larval fishes. Mar. Ecol. Prog. Ser. 50: 13-19.

Glazier, D.S. (2005). Beyond the '3/4-power law': variation in the intra-and interspecific scaling of metabolic rate in animals. Biol. Rev. 80: 611-662.

Glazier, D.S. (2008). Effects of metabolic level on the body size scaling of metabolic rate in birds and mammals. Proc. R. Soc. B. 275: 1405-1410.

Glazier, D.S. (2009). Activity affects intraspecific body-size scaling of metabolic rate in ectothermic animals. J. Comp. Physiol. B. 179: 821-828.

Glazier, D.S. (2010). A unifying explanation for diverse metabolic scaling in animals and plants. Biol. Rev. 85: 111-138.

Glazier, D.S. (2014a). Metabolic scaling in complex living systems. Systems 2: 451-540.

Glazier, D.S. (2014b). Scaling of metabolic scaling within physical limits. Systems 2: 425-450.

Glazier, D.S., Hirst A.G. and Atkinson, D. (2015). Shape shifting predicts ontogenetic changes in metabolic scaling in diverse aquatic invertebrates. Proc. R. Soc. B. 282: 20142302.

Goodman, R.M. and Heah, T.P. (2010). Temperature-induced plasticity at cellular and organismal levels in the lizard Anolis carolinensis. Integr. Zool. 5: 208-217.

Grigoriou, P. and Richardson, C.A. (2009). Effect of body mass, temperature and food deprivation on oxygen consumption rate of common cuttlefish Sepia officinalis. Mar. Biol. 156: 24732481.

Hermaniuk, A., Rybacki, M. and Taylor, J.R.E. (2016). Low temperature and polyploidy result in larger cell and body size in an ectothermic vertebrate. Physiol. Biochem. Zool. 89: 118-129.

Hirst A.G., Glazier, D.S. and Atkinson, D. (2014). Body shape shifting during growth permits tests that distinguish between competing geometric theories of metabolic scaling. Ecol. Lett. 17: 1274-1281.

Hölker, F. (2003). The metabolic rate of roach in relation to body size and temperature. J. Fish Biol. 62: 565-579.

Hölker, F. (2006). Effects of body size and temperature on metabolism of bream compared to 
387

388

389

390

391

392

393

394

395

396

397

398

399

400

401

402

403

404

405

406

407

408

409

410

411

412

413

414

415

416

417

sympatric roach. Anim. Biol. 56: 23-37.

Huang, Q.D., Zhang, Y.R., Liu, S.T., Wang, W. and Luo, Y.P. (2013). Intraspecific scaling of the resting and maximum metabolic rates of the crucian carp (Carassius auratus). PLoS One 8: e82837.

Hughes, G.M. (1966). The dimensions of fish gills in relation to their function. J. Exp. Biol. 45: 177-195.

Hughes, G.M. (1984). Scaling of respiratory areas in relation to oxygen consumption of vertebrates. Cell. Mol. Life Sci. 40: 519-524.

Itazawa, Y. and Oikawa, S. (1983). Metabolic rates in excised tissues of carp. Experientia 39: 160161.

Jobling, M. (1994). Fish Bioenergetics. London: Chapman and Hall.

Killen, S.S., Atkinson, D. and Glazier, D.S. (2010). The intraspecific scaling of metabolic rate with body mass in fishes depends on lifestyle and temperature. Ecol. Letters. 13: 184-193.

Kooijman, S.A.L.M. (2009). Dynamic energy budget theory for metabolic organization. Cambridge, UK, (Cambridge Univ. Press, Cambridge, UK).

Kozłowski, J., Konarzewski, M. and Gawelczyk, A.T. (2003). Cell size as a link between noncoding DNA and metabolic rate scaling. Proc. Natl. Acad. Sci. USA 100: 14080-14085.

Li, G., Lv, X., Zhou, J., Shen, C., Xia, D.Y., Xie, H. and Luo, Y.P. (2018). Are the surface areas of the gills and body involved with changing metabolic scaling with temperature? J. Exp. Biol. 221: 174474.

Luo, Y.P. and Wang, Q.Q. (2012). Effects of body mass and temperature on routine metabolic rate of juvenile largemouth bronze gudgeon Coreius guichenoti. J. Fish Biol. 80: 842-851.

Luo, Y.P., He, D.C., Li, G., Xie, H., Zhang, Y.R. and Huang, Q.D. (2015). Intraspecific metabolic scaling exponent depends on red blood cell size in fishes. J. Exp. Biol. 218(10): 1496-1503.

Luo, Y.P., Li, Q., Zhu, X.L., Zhou, J., Shen, C., Xia, D.Y., Djiba, P.K., Xie, H., Lv, X., Jia, J. and Li, G. (2020). Ventilation frequency reveals the roles of exchange surface areas in metabolic scaling. Physiol. Biochem. Zool. 93: 13-22.

Lv, X., Xie, H., Xia, D.Y., Shen, C., Li, J. and Luo, Y.P. (2018). Mass scaling of the resting and maximum metabolic rates of the black carp. J. Comp. Physiol. B. 188: 591-598.

Maciak, S., Janko, K., Kotusz, J., Choleva, L., Boron, A., Juchno, D., Kujawa, R., Kozłowski, J. and Konarzewski, M. (2011). Standard metabolic rate (SMR) is inversely related to 
418

419

420

421

422

423

424

425

426

427

428

429

430

431

432

433

434

435

436

437

438

439

440

441

442

443

444

445

446

447

448

erythrocyte and genome size in allopolyploid fish of Cobitis taenia hybrid complex. Funct. Ecol. 25: 1072-1078.

Melzner, F., Bock, C. and Pörtner, H.O. (2007). Allometry of thermal limitation in the cephalopod Sepia officinalis. Comp. Biochem. Physiol. A. 146: 149-154.

Newell, R.C. (1973). Factors affecting the respiration of intertidal invertebrates. Am. Zool. 13: 513-528.

Nico, L.G. and Neilson, M.E. (2019). Mylopharyngodon piceus (Richardson, 1846). U.S. Geological survey, nonindigenous aquatic species database, Gainesville, Florida. Available: https://nas.er.usgs.gov/queries/FactSheet.aspx?SpeciesID $=573$.

Ohlberger, J., Mehner, T., Staaks, G. and Hölker, F. (2008). Temperature-related physiological adaptations promote ecological divergence in a sympatric species pair of temperate freshwater fish, Coregonus spp. Funct. Ecol. 22: 501-508.

Ohlberger, J., Mehner, T., Staaks, G. and Hölker, F. (2012). Intraspecific temperature dependence of the scaling of metabolic rate with body mass in fishes and its ecological implications. Oikos 121: 245-251.

Ohlberger, J., Staaks, G. and Hölker, F. (2007). Effects of temperature, swimming speed and body mass on standard and active metabolic rate in vendace (Coregonus albula). J. Comp. Physiol. B. 177: 905-916.

Oikawa, S., Takemori, M. and Itazawa, Y. (1992). Relative growth of organs and parts of a marine teleost, the porgy, Pagrus major, with special reference to metabolism size relationships. Jap. J. Ichthyol. 39: 243-249.

Okie J.G. (2013). General models for the spectra of surface area scaling strategies of cells and organisms: fractality, geometric dissimilitude, and internalization. Am. Nat. 181: 421-439.

Paranjape, M.A. (1967). Molting and respiration respiration of Euphausiids euphausiids. J. Fish. Res. Board Can. 24: 1229-1240.

Peck, M.A., Buckley, L.J. and Bengtson, D.A. (2005). Effects of temperature, body size and feeding on rates of metabolism in young-of-the-year haddock. J. Fish Biol. 66: 911-923.

Phillips, R.B., Kondev, J., Theriot, J., Orme, N. and Garcia, H. (2009). Physical biology of the cell. Garland Science, New York.

R Development Core Team. (2018). R: a language and environment for statistical computing. R Foundation for Statistical Computing, Vienna. https:/www.R-project.org. 
449 Reich, P.B. (2001). Body size, geometry, longevity and metabolism: do plant leaves behave like $450 \quad$ animal bodies? Trends Ecol. Evol. 16: 674-680.

451 Rubner, M. (1883). Über den Einfluss einfluss der Kökörpergrösse auf Stoffstoff- und $452 \quad$ Kraftwechselkraftwechsel. Zeit. Biol. 19:535-562.

453 Sollid, J. and Nilsson, G.E. (2006). Plasticity of respiratory structures-adaptive remodeling of fish 454 gills induced by ambient oxygen and temperature. Resp. Physiol. Neurobi. 154: 241-251.

455 Sollid, J., Weber, R.E. and Nilsson, G.E. (2005). Temperature alters the respiratory surface area of crucian carp Carassius carassius and goldfish Carassius auratus. J. Exp. Biol. 208: 1109- 
480 Xie, X.J. and Sun, R.Y. (1990). The bioenergetics of the southern catfish (Silurus meridionalis Chen): resting metabolic rate as a function of body weight and temperature. Physiol. Zool. 63: 1181-1195.

Xiong, W., Zhu, Y., Zhu, X., Li, Q. and Luo, Y.P. (2020). Effects of gill excision and food deprivation on metabolic scaling in the goldfish Carassius auratus. J. Exp. Zool. A. 333: 194200.

Yoshiyama, K., and Klausmeier. C.A. 2008. Optimal cell size for resource uptake in fluids: a new facet of resource competition. Am. Nat. 171:59-70.

488 Zhang, Y.R., Huang, Q.D., Liu, S.T., He, D.C., Wei, G., Luo, Y.P. (2014). Intraspecific mass 489 scaling of metabolic rates in grass carp (Ctenopharyngodon idellus). J. Comp. Physiol. B. 184: 347-354. 


\section{Figure 1}

The relationship between resting metabolic rate $\left(\mathrm{RMR}, \mathrm{mg} \mathrm{O}_{2} \mathrm{~h}^{-1}\right)$ and body mass $(M, \mathrm{~g})$ of the black carp Mylopharyngodon piceus treated by two temperatures $\left(T,{ }^{\circ} \mathrm{C}\right)$ for two weeks.

The original data for variables including RMR and $M$ were $\log 10$ transformed. No significant interaction between $M$ and $T$ on RMR was observed using the general linear model $(\mathrm{g} / \mathrm{m})$. Then, the ordinary least squares regression $(\mathrm{Im})$ was performed on the RMR with $M$ and $T$. Red open circles and dashed line: $25^{\circ} \mathrm{C}$; black filled circles and solid line: $10^{\circ} \mathrm{C}$. 


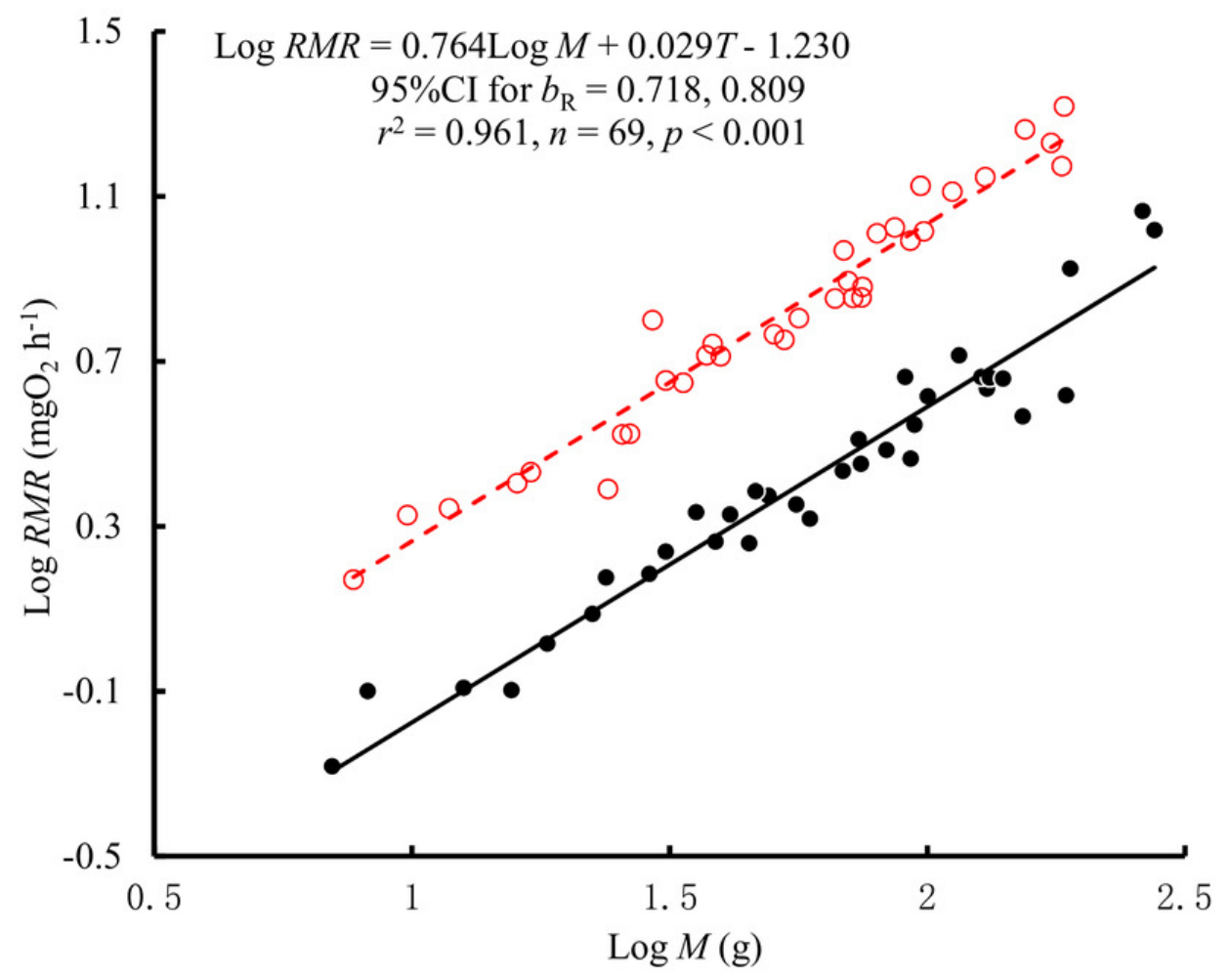




\section{Figure 2}

The relationship between gill surface area (GSA, $\mathrm{mm}^{2}$ ) and body mass $(M)$ of the black carp Mylopharyngodon piceus treated by two temperatures $\left(T,{ }^{\circ} \mathrm{C}\right)$ for two weeks.

No significant interaction between $M$ and $T$ on GSA was observed using the general linear model $(\mathrm{g} / \mathrm{m})$. Then, the ordinary least squares regression $(\mathrm{Im})$ was performed on the GSA with $M$ and $T$. Red open circles and dashed line: $25^{\circ} \mathrm{C}$; black filled circles and solid line: $10^{\circ} \mathrm{C}$. 


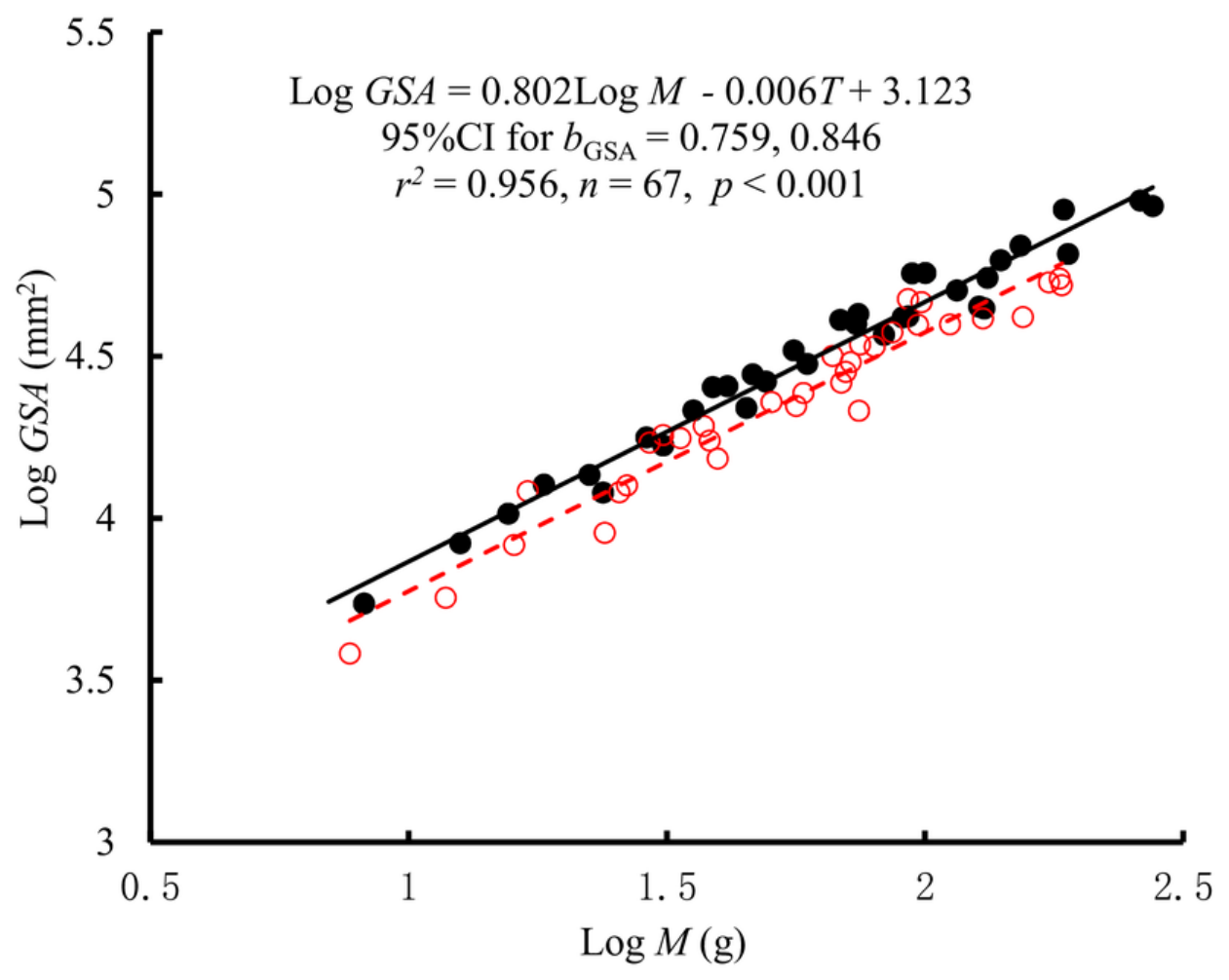


Figure 3

The relationship between red blood cell size $\left(S_{\mathrm{RBC}}, \mu \mathrm{m}^{2}\right)$ and mass of the black carp Mylopharyngodon piceus treated by two temperatures $\left(T,{ }^{\circ} \mathrm{C}\right)$ for two weeks.

No significant interaction between $M$ and $T$ on $S_{\mathrm{RBC}}$ was observed using the general linear model $(\mathrm{glm})$. Then, the ordinary least squares regression $(\mathrm{Im})$ was performed on the $S_{\mathrm{RBC}}$ with $M$ and $T$. Red open circles and dashed line: $25^{\circ} \mathrm{C}$; black filled circles and solid line: $10^{\circ} \mathrm{C}$. 


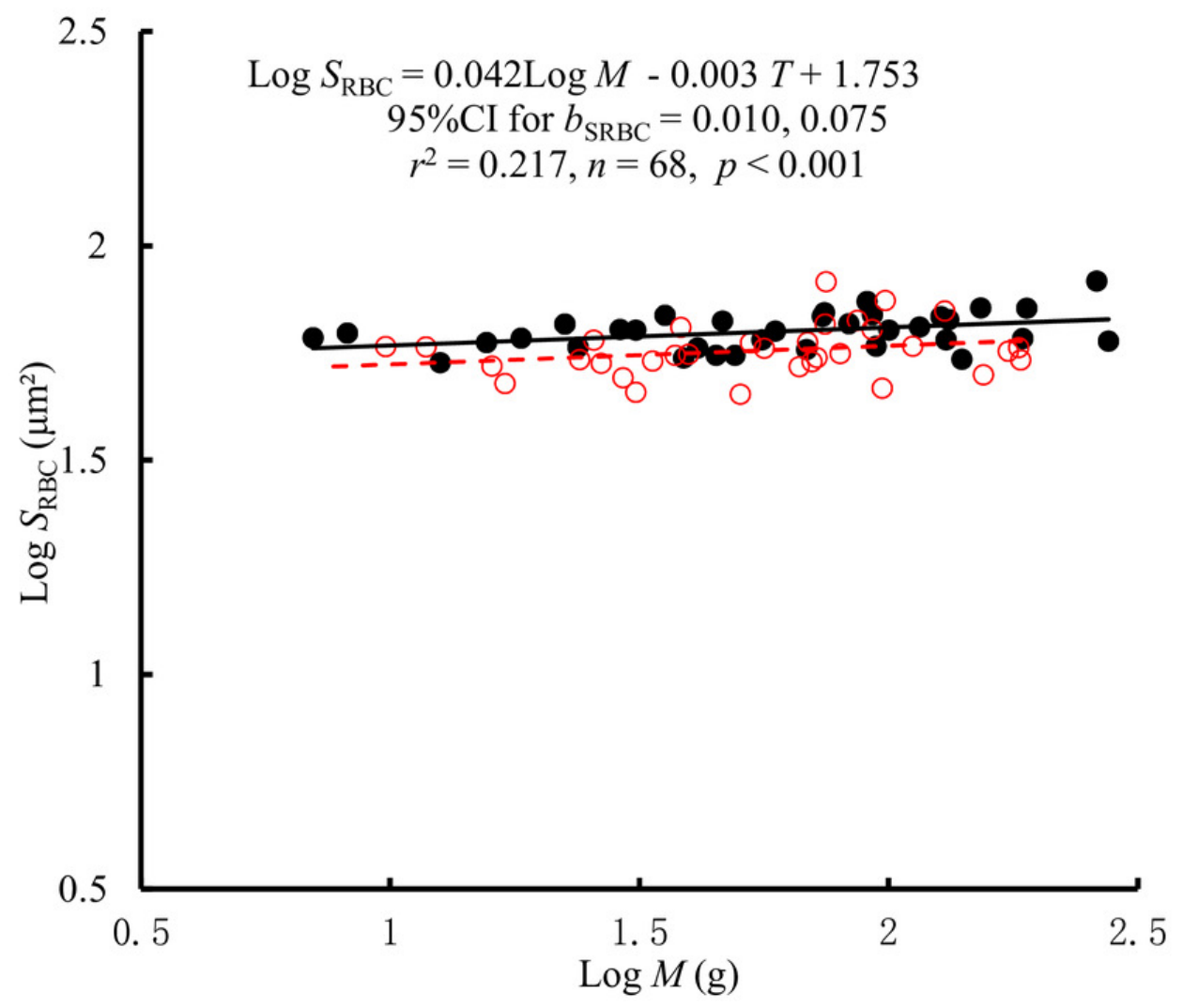

